\title{
Living in Contaminated Sites: Which Cost for Psychic Health?
}

\section{Fanny Guglielmucci, PsyD Student ${ }^{\star}$}

Department of Psychology, University of Turin (Italy)

fanny.guglielmucci@unito.it

\section{Isabella G. Franzoi, PsyD Student ${ }^{\star}$}

Department of Psychology, University of Turin (Italy) isabellagiulia.franzoi@unito.com

\section{Marco Zuffranieri, PsyD}

Department of Psychology, University of Turin (Italy) mzuffranieri@gmail.com

\section{Antonella Granieri, PsyD}

Department of Psychology, University of Turin (Italy) antonella.granieri@unito.it

\section{Doi:10.5901/mjss.2015.v6n4s3p207}

\section{Abstract}

\begin{abstract}
In this paper, we would like to offer a psychoanalytically oriented perspective on the psychic costs of most documented technological disasters (e.g. oil spill and nuclear accidents) or industrial pollution (e.g. asbestos manufacturing). We report a brief literature review about the relationship between Contaminated Sites (CSs) and mental health. The articles were selected from the most important medical and psychological databases: MEDLINE/Pubmed, PsycINFO and Proquest Psychology Journal. After electronic searches, we have manually reviewed reference lists from the identified publications. Literature review reveals that despite the specific kind of technological disasters (i.e. nuclear accidents, oil spill, asbestos manufacturing), the cost of survival is pretty much the same: anxiety, somatizations, rage, depression and post-traumatic conditions, which undermine one's own sense of psychic integrity. This cost seems to be even higher when people have to fight an invisible and boundless enemy, which threaten not only themselves but also their own children. Clinicians, mental health services and policy makers need to reflect upon these traumatic conditions in order to activate and promote a thinking process that can give rise to a new capability of containing all the experiential aspects that have remained alien, dissociated and unthinkable until that moment. Qualitative approaches and multi-dimensional analysis could lead a deeper understanding of the psychic dynamics and unconscious life in CSs.
\end{abstract}

Keywords: Contaminated Site (CS), Social Catastrophes, Mental Health, Massive Trauma, Technological Disaster

\section{Introduction}

Life can be punctuated by several catastrophic events: in some cases, these traumatic events involve only one person or a few individuals - such as serious accidents, threatening life assaults, aggressions or mourning - while in other cases an entire community or even more communities are exposed to social catastrophes.

The latter can be defined as overwhelming situations in which a massive and extreme trauma disrupts the foundations of the Self, such as affectivity, bodily integrity, the basic trust in the outside world, the sense of continuity and of personal agency ${ }^{1}$, and the ability to symbolize one's experience, giving meaning to life beyond trauma. Social catastrophes can also influence the subjective identity and compromise the capacity to engage in authentic and mutual

\footnotetext{
* These authors have contributed in the same part to the literature review and the writing of this paper.

1 Together with Franco Borgogno (2011), from a psychoanalytic perspective, by "agency" we mean the perception of one's own impact on the others, of one's personal effectiveness on the others, and the capability of engaging in personal and interpersonal actions.
} 
relationships with the others (Rosenbaum, \& Varvin, 2007).

Literature distinguishes between two main categories of social catastrophes: natural disasters - i.e. rapid or slow onset events that cause natural hazards such as geophysical changes or extreme climatic phenomena, which involve an entire population - and human-made disasters - such as complex emergencies connected to human actions or accidents. Research identifies several kinds of man-made massive traumatization, such as rape, conflict and war, terrorism, industrial pollution, nuclear radiation, etc. These traumatic experiences entail various and multifaceted consequences for the individuals, the community and the entire society: they may cause death, injury, illness or other health outcomes, as well as social and economic disruption or environmental degradation (Arata, Picou, Johnson, \& McNally, 2000; Borgogno F.V., Franzoi, Barbasio, Guglielmucci, \& Granieri, In press; Bromet, 2014; Crighton, Elliott, van der Meer, Small, \& Upshur, 2003; Erikson, 1994; Freudenburg, 1997; Guglielmucci, Franzoi, Barbasio, Borgogno F.V., \& Granieri, 2014; Neria, Nandi, \& Galea, 2008; Palinkas, 2012; Rosenbaum, \& Varvin, 2007; Volkan, 2004).

We think it is important to point out that even if most of the time these social catastrophes occur because of inhuman actions and irresponsible behaviors perpetrated in the name of profit, sometimes they are the results of accidents and human errors, or they may be secondary effects of natural catastrophes (Yamashita, \& Shigemura, 2013; Niitsu et al., 2014).

Developing a psychological perspective for understanding and responding to mental health effects of potential technological disasters, it is important to consider the peculiar characteristics of these events as well as similarities and differences between technological catastrophes, natural disasters and human disasters (Palinkas, 2012).

In a previous work, we suggested that "the exposure to a pathogen [is] a traumatic event that [can arouse] catastrophic affects, thus entailing the loss of healthy aspects of the Self" (Guglielmucci, Franzoi, Barbasio, Borgogno F.V., Granieri, 2014, p. 1419). These conditions, unpredictable and with long-term and widespread effects, represent a new and complex challenge for health services and clinicians. The exposure to a technological catastrophe has a negative impact on the physical health of the population, but also on its psychological component. Research identifies a variety of psychological variables involved, such as emotional distress, anxiety, somatization, depression, disruption of social relations, post-traumatic stress disorder (PTSD) (Arata, Picou, Johnson, \& McNally, 2000; Barnes, Baxter, Litva, \& Staples, 2002; Drescher, Schulenberg, \& Smith, 2014; Granieri, 2008; 2013; Granieri et al., 2013; Grattan, Roberts, Mahan, McLaughlin, Otwell, \& Glenn, 2011; Neria, Nandi, \& Galea, 2008; O'Leary, \& Covell, 2002; Osofsky, Osofsky, \& Hansel, 2011; Palinkas, Petterson, Russell, \& Downs, 1993; Sabucedo, Arce, Senra, Seoane, \& Vázquez, 2010; Yen et al., 2014). In addition, living in a CS has a great impact on the population's real and perceived risk of contamination exposure for the health status (Barnes, Baxter, Litva, \& Staples, 2002; Crighton, Elliott, van der Meer, Small, \& Upshur, 2003; Downey, \& Willigen, 2005; Foster, \& Goldstein, 2007). Moreover, even after the crisis is concluded, many individuals who have endured catastrophic trauma remain uncertain about having psychologically survived.

In this paper, we would like to focus our attention upon technological hazards originating from specific industrial conditions (i.e. nuclear radiation and industrial pollution) and to offer a psychoanalytically oriented perspective on the psychic costs of surviving and living in such a devastating reality. Our main intention is to underline the effects of most documented technological disasters (e.g. oil spill and industrial incidents such as the ones occurred in Chernobyl or Fukushima) or industrial pollution (e.g. asbestos manufacturing) on psychic health.

For this reason, we think it is important to report a brief literature review about the impact on mental health of technological disasters in relation to the type of event occurred. Our focus is on the most relevant literature that explores the relationship between CSs and psychological consequences of living there. The articles were selected from the most important medical and psychological databases: MEDLINE/Pubmed, PsycINFO and Proquest Psychology Journal. Electronic searches were conducted combining the following search terms: "environmental contamination"; "environmental exposure"; "environmental pollution"; "contaminated site"; "industrial contamination"; "industrial accident"; "asbestos"; "technological disaster"; "technological accident" AND "psychological impact"; "emotional distress". Finally, this search was augmented by manually reviewing reference lists from the identified publications.

\section{Contaminated Sites and Mental Health: A Brief Literature Review}

\subsection{Oil Spill Disasters}

During the years, several oil spill disasters have occurred all over the world. Taking into account only the major oil spills, the oldest one is the Torrey Canyon oil spill occurred on March 18 ${ }^{\text {th }}, 1967$ in the Isles of Scilly (UK), which created an oil slick measuring 270 square miles, contaminating 180 miles of coastland. Whereas, one of the latest ones is the Deepwater Horizon oil spill - also known as the Gulf oil spill - the largest in U.S. history. The Deepwater Horizon was a 
semi-submersible drilling rig, sank on April $22^{\text {nd }}, 2010$ after an explosion on the vessel. After several unsuccessful attempts to plug the well, oil flowed for more than 85 days reaching 572 miles of Gulf shoreline.

As we can see from the examples mentioned above, this kind of man-made disasters are characterized by the release of a liquid petroleum hydrocarbon into the environment - usually marine areas - and by an acute phase of pollution longer than the one that characterizes other types of disasters. Besides environment, oil spill disasters entail traumatic consequences also for the community involved, which have been defined as toxic or corrosive communities because of their prolonged oil exposure (Arata, Picou, Johnson, \& McNally, 2000; Baum, 1993; Baum, \& Fleming, 1993; Brown, \& Mikkelsen, 1997; Drescher, Schulenberg, \& Smith, 2014; Picou, Marshall, \& Gill, 2004). In these communities, we can trace profound feelings of rage and revenge, which often lead their members to undertake litigation aimed at seeking compensation for suffered damages (Picou, Marshall, \& Gill, 2004). The oil exposure has a deep impact on not only the resident populations' mental functioning, but also on community relationships. For people living there, it can be very harsh to cope with these traumatic situations: they can feel that they are almost alone in facing these dramatic circumstances, that they lack an adequate social support (Arata, Picou, Johnson, \& McNally, 2000; Drescher, Schulenberg, \& Smith, 2014). Often their trust in institutions, public officials and policy makers starts to waver (Couch, 1996; Erikson, 1994; Freudenburg, 1997).

Oil spill disasters have long-term consequences on the psyche: the results of a study conducted by Arata and colleagues (2000) after the Exxon Valdez oil spill occurred in 1989 in Alaska reveals that one-fifth of subjects involved in the research developed clinically significant anxiety symptoms and over one-third showed significant symptoms of depression or PTSD. Moreover, it seems that also the amount of time one is immersed in such a toxic environment has a significant influence on mental functioning: indeed, members of communities exposed to oil spill for a longer time referred higher levels of generalized anxiety disorder, PSTD and depression (Palinkas, Petterson, Russell, \& Downs, 1993). These findings seem to be supported by a recent study conducted on inhabitants of several locations along the coast of Galicia where the Prestige oil tanker sank in 2002 polluting thousands of kilometers of the Spanish, French and Portuguese coastline. (Sabucedo, Arce, Senra, Seoane \& Vázquez, 2010). This research discloses that individuals living nearby this CSs show a higher tendency to somatization, as well as more intense feelings of anxiety and hostility, a worse perceived physical health and a lower functional capacity. Furthermore, from a clinical perspective it is important to take into account that even communities only indirectly involved in oil spills pay a huge psychic cost reporting levels of psychological distress and depressive feelings similar to the ones that characterize communities directly exposed to this kind of social catastrophes (Grattan, Roberts, Mahan, McLaughlin, Otwell, \& Glenn, 2011).

As we suggested before, massive trauma can also compromise the ability to engage with others in both the personal and occupational domain. From this perspective, oil spills open the door to emotional distress, post-traumatic symptoms and other symptoms variously connected to psychic suffering and to mental health impairments. Furthermore, their impact seems to be more profound and severe for people who undergo the disruption of social and relational ties (Osofsky, Osofsky, \& Hansel, 2011).

A recent study conducted by Drescher, Schulenberg, and Smith (2014) seems to corroborate these results. This study was aimed at investigating the impact of the Gulf oil spill on the psychic health and involved a large clinical sample (1,119 people). For people living on the Mississippi Gulf Coast this technological disaster has represented a traumatic event difficult to cope with, which gave rise to depression, anxiety, and post-traumatic conditions. Thirty-nine percent of the sample showed clinically significant post-traumatic stress symptoms connected to the oil spill, symptoms which compromised and depauperated also social relationships.

\subsection{Industrial Accidents}

Living near industries and factories frequently offers economic well-being and prosperity to the individuals and the entire community, but when environmental hazards occur, there is a huge risk of psychic health and social ties "corrosion", thus creating what we can define as contaminated communities (Bush, Moffatt, \& Dunn, 2001).

In a recent literature review of papers published between 1980 and 2012, Pascal and colleagues (2013) focus on studies investigating the chronic effects of air pollution in large industrial areas. The authors underline that although many research highlight the impact on physic health (i.e. cancer and increased mortality rate), only three of them take into account the impact that a toxic environment could have on a mental level.

In the first research through a qualitative and bottom-up approach Bush and colleagues (Bush, Moffatt, \& Dunn, 2001) reveal that living in heavily industrialized areas and breathing toxic air can affect the identity of the place as well as the people living there. These conditions can also compromise the quality of social relationship, giving rise to intense feeling of loneliness and social marginalization. They can also influence the perception of the landscape, which for these 
people becomes a stigmatized place where to live.

The second study (Downey, \& Willigen, 2005) shows that residential proximity to industrial activities is a stressful event, which negatively affects individuals' mental health. This impact is both direct and indirect. In the first case, living near industrial facilities may increase individuals' levels of stress, making threats and negative fantasies connected to personal health conditions emerge. In the second case, this situation compromises the social structure of neighborhood, giving rise to psychological disorders and feelings of powerlessness, which in turn mediate on psychological distress.

Finally, the findings of the most recent study included in that review (Broadman, Dawney, Jackson, Merrill, Saint Onge, \& Williams, 2008) underline the relationship between residential proximity to the industrial activity and psychological distress using a multi-level model. More specifically, the authors argue that residential proximity to industrial activities is psychologically distressing and its negative impact is more pronounced for women than for men. Moreover, from a clinical perspective it is important to take into account that psychological distress connected to residential proximity has been found to be strongly influenced by occupational and parental status.

However, it is important to point out that environmental contamination can result not only from the constant emission of toxic substances, but also from industrial accidents. Over time, several man-made catastrophes have occurred and among these maybe the most tragic event still present in our minds is the Chernobyl nuclear catastrophes occurred in Ukraine on April $26^{\text {th }}, 1986$. For decades thousands of people all over Europe have been wounded - and still are nowadays - by the traumatic and devastating consequences of radiation exposure. The long-term effects of this unpredictable, unbelievable and meaningless human emergency are well known. A recent 25 years retrospective review on the psychic impact of this tragedy shows that long-term mental health consequences are still concerning and represent an important challenge for clinicians: in fact, even if two decades have passed, deep feelings of anxiety and depression, and PTSD symptoms remain elevated. Once again, even in this kind of technological disasters, the deeper negative impact on the psyche can be traced in resident mothers of young children, who report higher level of emotional distress, anxiety and hostility (Bromet, Harenaar, \& Guey, 2011). As Bromet (2012) pointed out, disasters involving nuclear radiation - such as the ones occurred in Chernobyl or in Fukushima, for example - are particularly difficult to manage: in these circumstances, the contaminating agent is invisible and pandemic, and causes lasting threatening consequences not only for physical health but also for mental health. Recently, this author suggested that the emotional consequences of Chernobyl nuclear disaster he investigated over the years are remarkably similar to those that can be traced after the Fukushima nuclear disaster (Bromet, 2014).

\subsection{Asbestos}

Among industrial contamination, the problem of diseases connected to asbestos is remarkably present and meaningful, even if its manufacturing is nowadays forbidden in many countries. Asbestos exposure is responsible for various pulmonary diseases, such as pleural plaques, diffuse pleural thickening, asbestosis, and - most notably - malignant pleural mesothelioma, a rare and fatal tumor. It has been shown that this disease affects both the workers and the entire community living nearby the asbestos manufacturing (Fazzo et al., 2012).

On a psychological level, the huge amount of victims deceased because of asbestos exposure cannot obfuscate the other threatening dimension connected with the diagnosis, that is above all the devastating impact of knowing that this pathology has affected or can affect a beloved person or even ourselves. In other words, the awareness of having been exposed and being still exposed to a lethal disease. According to the cause of the contamination and its consequences, communities exposed to asbestos become what we could define as dusted communities (Kozlowski, Provost, Tucker, \& van der Zwan, 2014).

Research shows that exposure to asbestos and the diagnosis of asbestos-related diseases can have a traumatic impact not only on patients and caregivers, but also on the entire community. This entails various consequences: psychological ones (such as depression, fears, anguish and anxieties) as well as relational ones (social retirement, loss of the sense of belonging and of social cohesiveness) (Arber \& Spencer, 2013; Clayson, Seymour, \& Noble, 2005; Dooley, Wilson, \& Anderson, 2010; Girgis, Lambert, Johnson, Waller, \& Currow, 2012; Granieri, 2008; 2013; Granieri et al., 2013; Guglielmucci, Franzoi, Barbasio, Borgogno F.V., \& Granieri, 2014; Maurel et al., 2009; McCormack, Peto, Byrnes, Straif, \& Boffetta, 2012; Mesothelioma UK: National Mesothelioma Experience Survey, 2012; Moore, Darlison, \& Tod, 2010; Northouse, Katapodi, Schafenacker, \& Weiss, 2012; Northouse, Katapodi, Song, Zhang, \& Mood, 2010). These intrapersonal and interpersonal consequences can be worsened by the presence of an invisible killer (i.e. asbestos, but also nuclear radiations and any other kind of air pollution). This activates the fantasy of and the fear for an aerial contagion, opening the door to catastrophic affects (Guglielmucci, Franzoi, Barbasio, Borgogno F.V., \& Granieri, 2014). As we pointed out elsewhere, from a psychoanalytically oriented point of view we would like to underline that living 
in a toxic environment can move unconscious conflicts between life and death, as well as feelings of helplessness, hopelessness, guilt, shame, rage and revenge (Borgogno F.V., Franzoi, Barbasio, Guglielmucci, \& Granieri, In press).

Moreover, bereaved caregiver often feel they have been "put aside" by the entire community, as if they had to be ashamed of having lost a beloved person in a way that anguishes everybody because it demonstrates and reminds the dangerousness of the place where they are still living (Borgogno F.V., Franzoi, Barbasio, Guglielmucci \& Granieri, In press; Granieri, \& Borgogno F. V., 2014). Following these perspective, it isn't surprising that people who are parents both men and women - show a higher level of stress, probably connected to the fact that living there they have somehow accepted something dangerous not only for themselves but also for their children (Guglielmucci, Franzoi, Barbasio, Borgogno F.V., \& Granieri, 2014).

\section{Conclusion}

Over the years, the world has witnessed many tragic events involving different kind of massive technological disasters. Surviving this kind of social catastrophes is not simple and very often people have to pay a considerable psychic cost.

Literature review reveals that despite the specific kind of technological disasters (i.e. nuclear accidents, oil spill, asbestos manufacturing), the cost of survival is pretty much the same: anxiety, somatizations, rage, depression and posttraumatic conditions, which undermine one's own sense of psychic integrity. The cost seems to be even higher when people have to fight an invisible and boundless enemy, which attacks not only themselves but also the life of their own children.

Beside the risk of an over-interpretation of the results of this literature review, we think it is important to reflect upon these from a clinical and psychoanalytically oriented perspective. As Volkan pointed out "Such statistical studies measuring observable manifestations of a trauma's lasting effects (anxiety, depression, or other signs of post-traumatic stress) may be misleading, however, insofar as they do not tell us much about individual minds or hidden, internal, psychological processes; apparent symptomatic uniformity may hide significant qualitative differences" (Volkan, 2014, p. 47).

For the victims of tragedies like the Gulf oil spill disaster as well as for the victims of asbestos manufacturing or of nuclear catastrophes occurred in Chernobyl or in Fukushima it is very difficult to manage the intensity of these catastrophic affect and there is a high risk of fragmentation. After the disaster, life goes on and the subject has to continue on living in a contradictory reality: in such traumatic circumstances intense fears connected to future, physical and mental health of either ourselves - or someone we love - emerge (Couch, 1996; Erikson, 1994; Freudenburg, 1996). Living in CSs has a negative effect on psyche and social relationships, but at the same time it also request clinicians, mental health services and policy makers to reflect upon these traumatic conditions in order to activate and promote a thinking process that can generate a change in the psychological space. This can give rise to a new capability of containing all the experiential aspects that have remained alien, dissociated and unthinkable until that moment.

Almost thirty years after the Chernobyl disaster, for example, the Chernobyl Forum showed that the main public health problem connected to the nuclear disaster was mental health (United Nations, 2006). As clinicians involved in helping traumatized people survive in CSs, we strongly believe that institutions have to go beyond alerting or reassuring exposed communities about potential environmental hazards. Instead, they need on the one hand to stimulate interest in environmental health issues, and on the other hand to increase individual, community and organizational awareness, and promote citizens involvement in decision making processes and in the development of a new trust in public health policy (Guglielmucci, Franzoi, Barbasio, Borgogno F. V., \& Granieri, 2014; Trettin \& Musham, 2000).

In these circumstances, in fact, the victims are overwhelmed by the fear that their plight will be overshadowed by new horrors occurring on the world stage.

One benefit of continuous monitoring and continuous research on mental and physical health connected to these catastrophes is that the work in itself symbolizes the long-term compassion and caring of investigators, including future generations. Although longitudinal cohort studies with appropriate comparison groups will ultimately produce the most useful data on incident health consequences (Svendsen et al. 2012), volunteer studies and convenience sampling designs (see for example Ben-Ezra, Palgi, Soffer, Y\& Shrira, 2012; Ben-Ezra et al., 2013; Kyutoku et al. 2012; Palgi et al. 2012) may also have a favorable effect. Moreover, we suggest that despite sophisticated statistical research strategies have increased our understanding upon psychological consequences of CSs, from a theoretic and clinical point of view it is important to combine these data with intensive single case research and the study of narratives of people living there (i.e. in depth-interview, audiotape, etc). It is important to consider that statistically identical events could be qualitatively profoundly different for people involved. From this perspective, qualitative approach and multi-dimensional analysis could lead a deeper understanding of the psychic dynamics and unconscious life in CSs, which in our opinion could not be 
understood only through standardized methods.

\section{References}

Arata, C. M., Picou, J. S., Johnson, G. D., \& McNally, T. S. (2000). Coping with technological disaster: an application of the conservation of resources model to the Exxon Valdez oil spill. Journal of Traumatic Stress, 13(1): 23-39. http://doi.org/10.1023/A:10077 64729337.

Arber, A., \& Spencer, L. (2013). "It"s all bad news': the first 3 months following a diagnosis of malignant pleural mesothelioma. PsychoOncology, 22(7): 1528-1533.

Barnes, G., Baxter, J., Litva, A., \& Staples, B. (2002). The social and psychological impact of the chemical contamination incident in Weston Village, UK: a qualitative analysis. Social Science \& Medicine, 55(12): 2227-2241. http://doi.org/10.1016/S0277-9536(01) 00367-7.

Baum, A. (1993). Implications of psychological research on stress and technological accidents. American Psychologist, $48(6), 665$.

Baum, A., \& Fleming, I. (1993). Implications of psychological research on stress and technological accidents. American Psychologist, 48(6): 665-72.

Ben-Ezra, M., Palgi, Y., Soffer, Y., \& Shrira, A. (2012). Mental health consequences of the 2011 Fukushima nuclear disaster: are the grandchildren of people living in Hiroshima and Nagasaki during the drop of the atomic bomb more vulnerable? World Psychiatry, 11: 133.

Ben-Ezra, M., Palgi, Y., Aviel, O., Dubiner, Y., Baruch, E., Soffer, Y., \& Shrira, A. (2013). Face it: collecting mental health and disaster related data using Facebook vs. personal interview: the case of the 2011 Fukushima nuclear disaster. Psychiatry Research, 208: 91-93.

Borgogno, F. (2011). The girl who committed Hara-Kiri and other clinical and historical essay, London: Karnak Books 2013.

Borgogno, F. V., Franzoi, I. G., Barbasio, C. P., Guglielmucci, F., \& Granieri, A. (In press) Massive Trauma in a Community Exposed to Asbestos: Thinking and Dissociation in the Population of Casale Monferrato. British Journal of Psychotherapy.

Boardman, J. D., Downey, L., Jackson, J. S., Merrill, J. B., Saint Onge, J. M., \& Williams, D. R. (2008). Proximate industrial activity and psychological distress. Population and Environment, 30(1-2): 3-25. http://doi.org/http://dx.doi.org.offcampus.dam.unito.it/ 10.1007/s11111-008-0075-8.

Bromet, E. J. (2012). Mental health consequences of the Chernobyl disaster. Journal of Radiological Protection, 32(1): N71-5. doi: $10.1088 / 0952-4746 / 32 / 1 / N 71$.

Bromet, E. J. (2014). Emotional Consequences of Nuclear Power Plant Accidents. Paper presented at the Third International Expert Symposium in Fukushima: Beyond Radiation and Health Risk-Toward Resilience and Recovery. Fukushima: 8-9 September 2014.

Bromet, E. J., Harenaar, J. M., \& Guey, L. T. (2011). A 25 year retrospective review of the psychological consequences of the Chernobyl accident. Clinical Oncology (Royal College of Radiologists), 23(4): 297-305.

Brown, P., \& Mikkelsen, E. J. (1997). No safe place: Toxic waste, leukemia, and community action. Berkeley: University of California Press.

Bush, J., Moffatt, S., \& Dunn, C. (2001). «Even the birds round here cough»: stigma, air pollution and health in Teesside. Health \& Place, $7(1): 47-56$

Clayson, H., Seymour, J., \& Noble, B. (2005). Mesothelioma from the Patient's Perspective. Hematology/Oncology Clinics of North America, 19(6): 1175-1190.

Couch, S. R. (1996). Environmental contamination, community transformation and the Centralia mine fire: Toward a stage model for industrial contamination. In J. K. Mitchell (Ed.). Community response to industrial disasters. New York: United Nations University Press.

Crighton, E. J., Elliott, S. J., van der Meer, J., Small, I., \& Upshur, R. (2003). Impacts of an environmental disaster on psychosocial health and well-being in Karakalpakstan. Social Science \& Medicine, 56(3): 551-567.

Dooley, J. J., Wilson, J. P., \& Anderson, V. A. (2010). Stress and depression of facing death: Investigation of psychological symptoms in patients with mesothelioma. Australian Journal of Psychology, 62(3): 160-168.

Downey, L., \& Willigen, M. V. (2005). Environmental Stressors: The Mental Health Impacts of Living Near Industrial Activity. Journal of Health and Social Behavior, 46(3): 289-305.

Drescher, C. F., Schulenberg, S. E., \& Smith, C. V. (2014). The Deepwater Horizon Oil Spill and the Mississippi Gulf Coast: Mental health in the context of a technological disaster. The American Journal of Orthopsychiatry, 84(2): 142-151. http://doi.org/10. $1037 / \mathrm{h} 0099382$.

Erikson, K. (1994). A new species of trouble: The human experience of modern disasters. New York: Norton.

Fazzo, L., Minelli, G., De Santis, M., Bruno, C., Zona, A., Marinaccio, A., Conti, S., Pirastu, R., \& Comba, P. (2012). Mesothelioma mortality surveillance and asbestos exposure tracking in Italy. Annali dell'Istituto Superiore di Sanità, 48(3): 300-310.

Foster, R. P., \& Goldstein, M. F. (2007). Chernobyl disaster sequelae in recent immigrants to the United States from the former Soviet Union (FSU). Journal of Immigrant and Minority Health, 9(2): 115-124.

Freudenburg, W. R. (1997). Contamination, corrosion, and the social order: An overview. Current Sociology, 45: $19-40$.

Girgis, A., Lambert, S., Johnson, C., Waller, A., \& Currow, D. (2012). Physical, psychosocial, relationship, and economic burden of caring for people with cancer: a review. Journal of Oncology Practice, 9(4): 197-202. doi: 10.1200/JOP.2012.000690. 
Granieri, A. (2008). Amianto, risorsa e dramma di Casale: risvolti psicologici nelle persone affette da mesotelioma e nei loro familiari. [Asbestos: resource and tragedy for Casale Monferrato. Psychological aspects in people affected by malignant pleural mesothelioma and in their caregivers]. Genova: Fratelli Frilli Editori

Granieri, A. (2013). L'amiante, la double peine. Casale Monferrato: atteintes physiques, traumatismes psychologiques, résistances. [Asbestos, the double pain. Physical harm, psychological trauma and resilience]. Fréjus: Sudarenes

Granieri, A., Tamburello, S., Tamburello, A., Casale, S., Cont, C., Guglielmucci, F., \& Innamorati, M. (2013). Quality of Life and Personality Traits in Patients with Malignant Pleural Mesothelioma and Their First-Degree Caregivers. Neuropsychiatric Disease and Treatment, 9: 1193-202.

Grattan, L. M., Roberts, S., Mahan, W. T., McLaughlin, P. K., Otwell, W. S., \& Morris, J. G. (2011). The early psychological impacts of the Deepwater Horizon oil spill on Florida and Alabama communities. Environmental Health Perspectives, 119(6): 838-843. http://doi.org/10.1289/ehp.1002915.

Guglielmucci, F., Franzoi, I. G., Barbasio, C. P., Borgogno, F. V., \& Granieri, A. (2014). Helping Traumatized People Survive: a Psychoanalytic Intervention in a Contaminated Site. Frontiers in Psychology, 5:1419. DOI 10.3389/fpsyg.2014.01419.

Kozlowski, D., Provost, S. C., Tucker, J., \& van der Zwan, R. (2014). Dusted community: Piloting a virtual peer-to-peer support community for people with an asbestos-related diagnosis and their families. Journal of Psychosocial Oncology, 32(4): 463-475.

Kyutoku, Y., Tada, R., Umeyama, T., Harada, K., Kikuchi, S., Watanabe, E., Liegey-Dougall, A., \& Dan, I. (2012). Cognitive and psychological reactions of the general population three months after the 2011 Tohoku earthquake and tsunami. PLoSOne, 7: e31014.

Maurel, M., Stoufflet, A., Thorel, L., Berna, V., Gislard, A., Letourneux, M., ..., \& Paris, C. (2009). Factors associated with cancer distress in the Asbestos Post-Exposure Survey (APEXS). American Journal of Industrial Medicine, 52(4): 288-296.

McCormack, V., Peto, J., Byrnes, G., Straif, K., \& Boffetta, P. (2012). Estimating the asbestos-related lung cancer burden from mesothelioma mortality. British Journal of Cancer, 106(3): 575-584. doi: 10.1038/bjc.2011.563.

Mesothelioma UK (2012). National Mesothelioma Experience Survey. Retrieved online at http://www.mesothelioma.uk.com.

Moore, S., Darlison, L., \& Tod, A. M. (2010). Living with mesothelioma. A literature review. European Journal of Cancer Care, 19(4): 458-468.

Neria, Y., Nandi, A., \& Galea S. (2008). Post-traumatic stress disorder following disasters: a systematic review. Psychological Medicine, 38: 467-480.

Niitsu, T., Takaoka, K., Uemura, S., Kono, A., Saito, A., Kawakami, N., ... Shimizu, E. (2014). The psychological impact of a dualdisaster caused by earthquakes and radioactive contamination in Ichinoseki after the Great East Japan Earthquake. BMC Research Notes, 7: 307. http://doi.org/10.1186/1756-0500-7-307.

Northouse, L. L., Katapodi, M. C., Schafenacker, A. M., \& Weiss, D. (2012). The impact of caregiving on the psychological well-being of family caregivers and cancer patients. Seminars in Oncology Nursing, 28(4): 236-245.

Northouse, L. L., Katapodi, M. C., Song, L., Zhang, L., \& Mood, D. W. (2010). Interventions With Family Caregivers of Cancer Patients: Meta-Analysis of Randomized Trials. A Cancer Journal for Clinicians, 60: 317-339.

O'Leary, J., \& Covell, K. (2002). The Tar Ponds kids: Toxic environments and adolescent well-being. Canadian Journal of Behavioural Science/Revue canadienne des sciences du comportement, 34(1): 34-43.

Osofsky, H. J., Osofsky, J. D., \& Hansel, T. C. (2011). Deepwater horizon oil spill: mental health effects on residents in heavily affected areas. Disaster Medicine and Public Health Preparedness, 5(4): 280-286. http://doi.org/10.1001/dmp.2011.85.

Palgi, Y., Ben-Ezra, M., Aviel, O., Dubiner, Y., Baruch, E., Soffer, Y., \& Shrira, A. (2012). Mental health and disaster related attitudes among Japanese after the 2011 Fukushima nuclear disaster. Journal Psychiatric Research,46: 688-690.

Palinkas, L. A. (2012). A Conceptual Framework for Understanding the Mental Health Impacts of Oil Spills: Lessons from the Exxon Valdez Oil Spill. Psychiatry, 75(3): 203-22. http://doi.org/http://dx.doi.org.offcampus.dam.unito.it/101521psyc2012753203.

Palinkas, L. A., Petterson, J. S., Russell, J., \& Downs, M. A. (1993). Community patterns of psychiatric disorders after the Exxon Valdez oil spill. The American Journal of Psychiatry, 150(10): 1517-1523.

Pascal, M., Pascal, L., Bidondo, M.-L., Cochet, A., Sarter, H., Stempfelet, M., \& Wagner, V. (2013). A review of the epidemiological methods used to investigate the health impacts of air pollution around major industrial areas. Journal of Environmental and Public Health, 737926. http://doi.org/10.1155/2013/737926.

Picou, J. S., Marshall, B. K., \& Gill, D. A. (2004). Disaster, litigation, and the corrosive community. Social Forces, 82(4): $1493-1522$.

Rosenbaum, B. \& Varvin, S. (2007). The influence of extreme traumatization on body, mind, and social relations. International Journal of Psycho-Analysis, 88: 1527-1542.

Sabucedo, J. M., Arce, C., Senra, C., Seoane, G., \& Vázquez, I. (2010). Symptomatic profile and health-related quality of life of persons affected by the Prestige catastrophe. Disasters, 34(3): 809-820. http://doi.org/10.1111/j.1467-7717.2010.01170.x.

Svendsen, E. R., Runkle, J. R., Dhara, V.R., Lin, S., Naboka, M., Mousseau, T. A., \& Bennett, C. L. (2012). Epidemiologic methods lessons learned from environmental public health disasters: Chernobyl, the World Trade Centre, Bhopal, and Graniteville, South Carolina. International Journal of Environmental Research and Public Health, 9:2894-2909.

Trettin, L., \& Musham, C. (2000). Is trust a realistic goal of environmental risk communication. Environment and Behavior, 32(3): 410426.

United Nations (2006). The Chernobyl forum: 2003-2005. Vienna, Austria: United Nations, 2006.

Volkan, V. D. (2004) Traumatized Societies and Psychological Care: Expanding the Concept of Preventive Medicine. In D. Knafo (Ed.). Living With Terror, Working With Trauma: A Clinician's Handbook. New York, NY: Jason Aronson. 
Volkan, V. D. (2014). Psychoanalysis, International Relations, and Diplomacy: A Sourcebook on Large-Group Psychology. London: Karnac.

Yamashita, J., \& Shigemura, J. (2013). The Great East Japan Earthquake, tsunami, and Fukushima Daiichi nuclear power plant accident: a triple disaster affecting the mental health of the country. The Psychiatric Clinics of North America, 36(3): 351-370. http://doi.org/10.1016/j.psc.2013.05.004.

Yen, P. N., Lin, I.-F., Chang, W. P., Wang, J.-D., Chang, T.-C., Kuo, K.-L., ..., \& Yang, C.-C. (2014). Risk factors of depression after prolonged low-dose rate environmental radiation exposure. International Journal of Radiation Biology, 90(10): 859-866. http://doi.org/10.3109/09553002.2014.916830. 